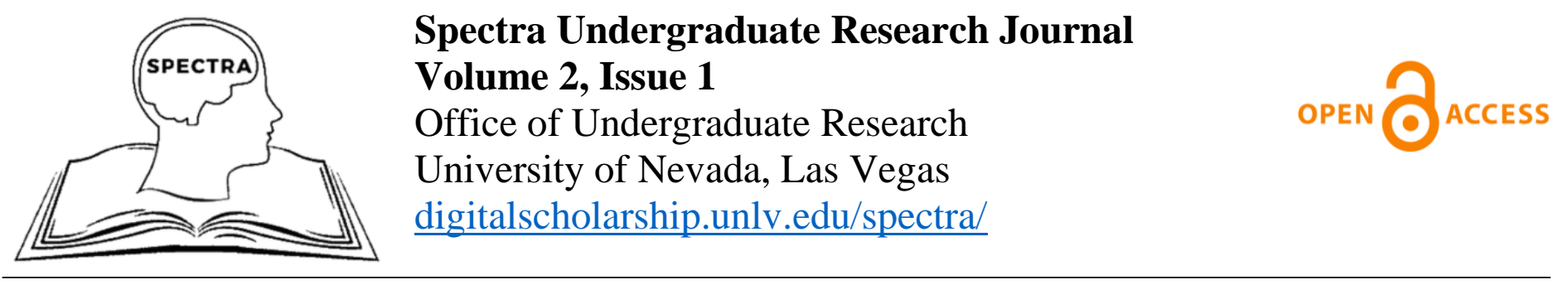

\begin{tabular}{|c|}
\hline Category \\
\hline Arts, Humanities, and Social Sciences $>$ Social Sciences $>$ Political Science \\
\hline Received \\
\hline December 21,2021 \\
\hline Accepted \\
\hline February 1,2022 \\
\hline Published \\
\hline February 28,2022 \\
\hline Article Title \\
\hline How Do Teachers' Unions Influence Vaccine Mandates? \\
\hline Authors \\
\hline Kristian Thymianos $(\mathrm{KT})^{1 *}$ \\
\hline Author Affiliations \\
\hline${ }^{1}$ Department of Political Science, University of Nevada, Las Vegas, Las Vegas, NV, USA. \\
\hline Corresponding Author \\
\hline *Kristian Thymianos, kristian.thymianos@unlv.edu \\
\hline Author Contributions \\
\hline KT: Data collection, data analysis, methodology, and writing of the manuscript \\
\hline Copyright \\
\hline 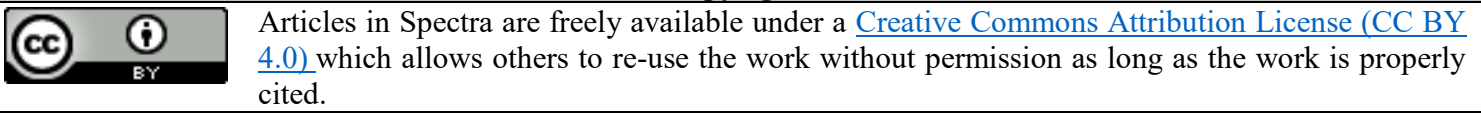 \\
\hline ISSN \\
\hline $2766-7227$ \\
\hline Data Availability Statement \\
\hline $\begin{array}{l}\text { The author confirms that all data underlying the findings are fully available without restrictions upon request. } \\
\text { Conflicts of Interest }\end{array}$ \\
\hline The author declares that no conflicts of interest exist. \\
\hline Ethical Considerations \\
\hline $\begin{array}{l}\text { Given that this project did not involve human or animal subjects, no IRB or IACUC approval was needed. All research } \\
\text { was derived from publicly shared sources. }\end{array}$ \\
\hline Funding \\
\hline No funding was used to conduct this research. \\
\hline Recommended Citation \\
\hline $\begin{array}{l}\text { Thymianos, K. (2022). How do teachers' unions influence vaccine mandates? Spectra Undergraduate Research } \\
\text { Journal, 2(1), 47-53. https://doi.org/10.9741/2766-7227.1015 }\end{array}$ \\
\hline
\end{tabular}




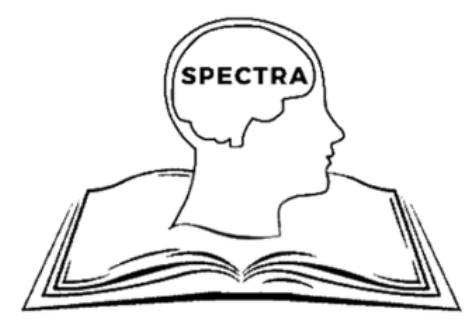

Spectra Undergraduate Research Journal

Volume 2, Issue 1

Office of Undergraduate Research

University of Nevada, Las Vegas

digitalscholarship.unlv.edu/spectra/

\title{
How Do Teachers' Unions Influence Vaccine Mandates?
}

\section{Kristian Thymianos ${ }^{1}$}

\section{Author Affiliations:}

${ }^{1}$ Department of Political Science, University of Nevada, Las Vegas, Las Vegas, NV, USA.

\begin{abstract}
The COVID-19 pandemic presented an array of policy problems for school districts across the country. This included balancing social distancing during in-person learning. The creation of the COVID-19 vaccine made in-person learning a more viable option again. However, the political polarization that surrounded COVID-19 extended to vaccines, with many communities experiencing hurdles in vaccinating their populace. Previous research shows how teachers' unions influenced school district reopenings during the height of the pandemic in fall of 2020; this paper seeks to expand on this literature by looking at how teachers' unions influence the adoption of vaccination mandates and testing. I test whether a school district has a collective bargaining agreement (CBA) with a teachers' union, the page length of that CBA. Using an OLS regression, I find that if a teachers' union has a CBA with its school district, the district is $33 \%$ more likely to adopt a vaccination and testing mandate than a district without a CBA. Additionally, the page length CBA has a weaker, but still significant relationship in encouraging the adoption of a vaccination and testing mandate in a school district.
\end{abstract}

Keywords: Teachers' unions, COVID-19, vaccination mandates, collective bargaining

As COVID-19 began spreading through the United States in March of 2020, state governments across the country declared states of emergencies and shut down their states. Figuring out how to safely continue education in school districts became a large policy concern as children's learning was disrupted. Online learning became the dominant form of learning for students. However, online learning encountered many problems. Besides the difficulties in acquiring technology to sustain online learning like internet connection and laptops, evidence suggests that online learning was not as effective as learning in person, especially for younger students (Tomasik et al., 2021). When the school year in the fall of 2020 began, involved parties, such as school districts, unions, state and local governments, assessed the costs and benefits of returning to in-person learning. The politically polarized narratives regarding COVID-19 made the discussions on how to approach the 2020-2021 school year difficult. Groups had to be organized and possess the power to achieve preferred outcomes. As the vaccine against COVID-19 came into play, this opened up new discussions on how to fight the pandemic and protect populations in schools.

In this paper, I examine how teachers' unions influence the adoption of COVID-19 vaccination mandates in their school districts. I leverage my own dataset of 49 school districts and their collective bargaining agreements (CBAs) against the vaccination policies that the school districts adopt. I find that a district with a CBA is $33 \%$ more likely to adopt a vaccination and test mandate, and that there is some support for the argument that the more pages in a CBA, the more likely the school district will adopt a vaccination and testing mandate. These findings add to the discussion of how teachers' unions have influenced school district policies as it relates to the COVID-19 pandemic. This helps illuminate the potential roles that 
unions may play in the event of future public health crises.

The paper is structured as follows. In the first section I discuss the current events of how COVID-19 has affected the education system in the U.S. and the literature that proceeded to explain how teachers' unions influenced changing situations in school districts. Then I provide an explanation for the variables used in this study. In the second section, I describe the collection of those variables in detail. Next, section three covers the analysis of the collected data. Lastly, I provide concluding remarks, and where this research can be expanded upon.

\section{Theories of Unions and how they respond to COVID-19 \\ COVID-19 and Unions}

As states across the country shut down economies and forced lockdowns onto their citizens, school districts had to contend with teaching children remotely. While federal funding supplied capital to close many online infrastructure gaps (Jordan, 2021), teaching in-person was still preferred due to online learning not being as effective. However, there are still costs associated with in-person learning. The main costs were increased potential exposure to COVID-19, the capital required to increase sanitary standards, exacerbated staffing issues, and the lack of space to maintain social distancing. Additionally, there were chances of further disruption to learning by switching from in-person back to online learning due to COVID19 outbreaks. The benefits, on the other hand, were that students were likely to have better educational outcomes under in-person learning, opportunities for children to socialize, arguably less technological issues, and it would reduce costs of parents caring for their children at home to do other things like go to work. In sum, there are several aspects to consider when districts go back in-person. Teachers' unions play an important role here by representing teachers in these discussions. Given that teachers bear a number of these listed burdens and more, it is the union's responsibility to mitigate these burdens for its members.

Unfortunately, there continue to be broader political disagreements on how to balance a return to pre-COVID-19 living while the disease still spreads across the country. These debates impact the discussions on reopening schools. The main point of contention since the late summer and fall of 2020 is whether we should adopt more restrictions to mitigate the spread of the virus, such as mask mandates, social distancing, and vaccination mandates, or if we should limit or have no restrictions at all as a way to return to pre-COVID-19 living. The politicization of the issue was very public with then-President Trump pushing for schools to reopen in the fall of 2020 despite experts warning otherwise (Feuer, 2020). Partisanship prevented policy solutions to stem the virus, with Democrats being more "pro-restriction" than Republicans who were more "anti-restriction" (Grossman et al., 2021). Since policies to prevent further COVID-19 spread were being stalled, teachers' unions played a large role in getting such policies passed. Many studies looked at union influence in school districts and found that school districts with stronger teachers' unions were more likely to delay teaching in-person (DeAngelis \& Makridis, 2021; Hartney \& Finger, 2021; Marianno et al., 2021) or even adopt mandates for school populations to wear masks to prevent the spread of COVID-19 (Dean et al., 2021).

The primary way to return to a safe, in-person learning environment is to have a substantial amount of each school district's community vaccinated against COVID-19 because increased immunity stems the impact and spread of the disease. The introduction of the COVID-19 vaccines and their widespread access in the spring of 2021 offered a chance to mitigate the advancement of the disease across the country. Yet the disagreements on vaccines and vaccination mandates are a barrier to fighting COVID-19. Given the influence that teachers' unions had on the reopening of schools during the 2020-2021 school year (Hemphill \& Marianno, 2021), it is pertinent to ask, how do teachers' unions influence the adoption of vaccination mandates for employees in school districts? Do teachers' unions even have an incentive to support employee vaccination mandates? The push for online learning suggests they likely support the mandates. Unions have a vested interest in keeping their members safe. The lack of large vaccination rates endangers their members. Thus, they should have a preference towards some kind of incentive for school staff to get vaccinated.

Unfortunately, the polarization around vaccines presents an internal problem for unions. If 
there were to be a strict vaccine mandate and teachers outright refused to get vaccinated, unions would lose membership and school districts would lose teachers. Therefore, unions and districts may be averse to a strict vaccination mandate. Instead, the they may prefer a vaccination and testing mandate. The difference between strict vaccination mandates and vaccination and testing mandates is that the vaccination and testing mandate gives the teachers the option to avoid vaccinations by taking periodic COVID-19 tests. This is in contrast to the vaccination mandate which requires all staff get vaccinated. Vaccination and testing mandates still ensure some degree of safety for people in schools by tracking COVID-19 cases that may occur. Additionally, the vaccination and testing mandate keeps pressure on teachers and staff to get vaccines to avoid the costs associated with having to get tested for COVID-19 and wait for results periodically.

\section{Theories of Group Power}

Assuming unions prefer vaccination and testing mandates, I am concerned with whether a union is able to influence a school district to adopt a vaccination and testing mandate. My research question is then: does the strength of a teachers' union predict whether a school district will adopt a COVID-19 vaccination and testing mandate? Measuring the strength of a teachers' union is necessary in this case. The strength of the teachers' unions will be measured using Marianno et al.'s (2021) methodology. Marianno et al. (2021) used Bachrach and Baratz (1962) theory of interest group power and found that unions with longer-term collective bargaining, otherwise more entrenched power, were more likely to delay in-person learning. Collective bargaining agreements (CBAs) are contracts that typically set salaries, class sizes, planning periods, and spending levels (Hoxby, 1996; Rose \& Sonstelie 2010; Strunk, 2011). However, CBAs will likely have few or no mentions of COVID-19 related policies because these contracts can last several years. This is why Marianno et al.'s (2021) use of Bachrach and Baratz's (1962) theory can be advantageous. Bachrach and Baratz (1962) focused on the two faces of power that were exercised by groups to influence others. There is the short face of power and the long face of power. The short face of power includes tactics that groups use which are visible to the public. These tactics are in reaction to proposed policies and hope to influence the outcome of said policy. For example, when groups make official statements to the press in regards to a salient topic, this would be considered a use of the first face of power. The long face of power, however, is a deterrence tactic against unfavorable policies so that the policies will not be put on agendas in the first place. An example of the second face of power is when groups use their connections with other important groups or individuals outside the public sphere to influence policies and agendas before those policies and agendas are even set. In other words, groups exercising the second face of power use their influence amongst contained groups that have direct influence on the outcome of policies. This is opposed to involving the public in an effort to expand the conflict to the groups benefit as the short face of power does. Due to data limitations, I will not focus on the short face of power. However, this is not too concerning since Marianno et al. (2021) did not find statistical significance for the short face of power in their paper.

In this analysis, I will utilize CBAs between teachers' unions and school districts for the long face of power. CBAs serve as a good measure for the long face of power because they show that the union has bargaining capabilities with the school district and a likelier chance of accomplishing its goals that would be difficult without the CBA. To elaborate, unions with CBAs could entrench their power within the school districts by negotiating a contract with their districts. Unions with CBAs have more leverage, and do not need to expand their conflicts with school districts to the public as much as a union without a CBA does. With that, I also surmise that the longer a CBA, the more likely that a school district would adopt a vaccination and testing mandate. This is because a CBA with more pages indicates more rights, regulations, and other guarantees in favor of the union - in other words, it indicates a stronger union.

Therefore, I am left with two hypotheses: Hypothesis A: a school district that has a CBA with a teachers' union is more likely to adopt a vaccination and testing mandate than a school district without a $C B A$.

Hypothesis B: the more pages in a CBA between a teacher's union and a school district the more likely 
the school district will adopt a vaccination and testing mandate.

\section{Data}

\section{Independent Variables}

To gather the data, I located the largest 50 school districts in the country from the National Center for Education Statistics (2021). Then, I collected unique data on union strength by looking at each school district to see what teachers' union the school districts negotiated with and whether the union had a CBA. This information is typically found in labor relation sections of school district websites and, occasionally, within the websites of teachers' unions under negotiated contract sections. Some states ban collective bargaining. Those states being Texas, North Carolina, Tennessee, and Georgia. Thus, school districts in these states were documented as having no CBA. When I could not locate a CBA in a school district, I contacted the school district and/or the teachers union to see if they had a CBA in place. If a school district was in the process of negotiating a CBA and did not have one for the 20212022 school year but did have a CBA for the 20202021 school year, the older contract was used. This is because previous research found that the length of CBAs is relatively static over time (McDonnell \& Pascal, 1988; Cowen \& Fowles, 2013; Ingle \& Wisman, 2017). Thus, using the older ones should not be a problem for this study.

To measure the relative strength of teachers' union CBAs, I then documented the number of pages for the CBA by hand. I use this as one of the independent variables to proxy the strength of a teachers' union in relation to Marianno et al. (2021) that found a moderate negative relationship for the number of pages in a CBA and the likelihood that a school district will teach in person during the fall 2020 semester of the COVID-19 pandemic. The rationale here is that the more pages there are in a CBA, the power of a teachers' union is broader and more nuanced. Therefore, theoretically, a CBA with 426 pages would indicate that this teachers' union would be more powerful than a union with a 50-page CBA or one without a CBA at all.

From this data, I created two independent variables: the presence of a CBA and the number of pages in the CBA. The first independent variable, whether there were CBAs, is a binary variable coded as a 1 being the presence of a CBA and a 0 being the absence of a CBA. Figure 1 shows data about this variable. The average of this variable is 0.571 , meaning that of the sampled districts, most had a collective bargaining agreement.

\section{Figure 1}

Number of CBA Agreements

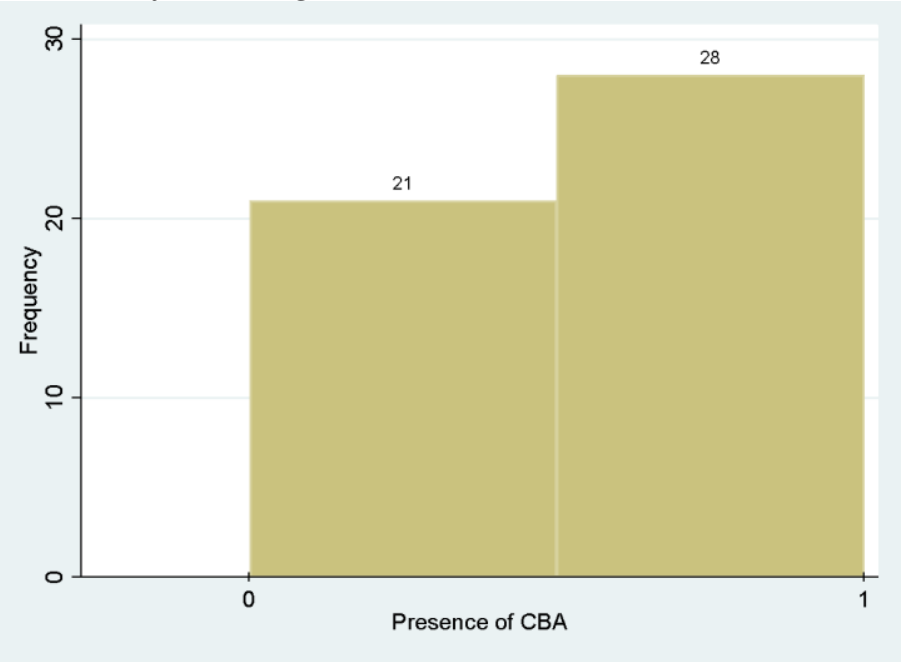

The second independent variable, the CBA page numbers, is a ratio variable indicating the number of pages in a CBA. The average pages in an agreement are 82 pages with a range of 0 to 426 pages. This information is displayed in Figure 2.

\section{Figure 2}

CBA Page Numbers

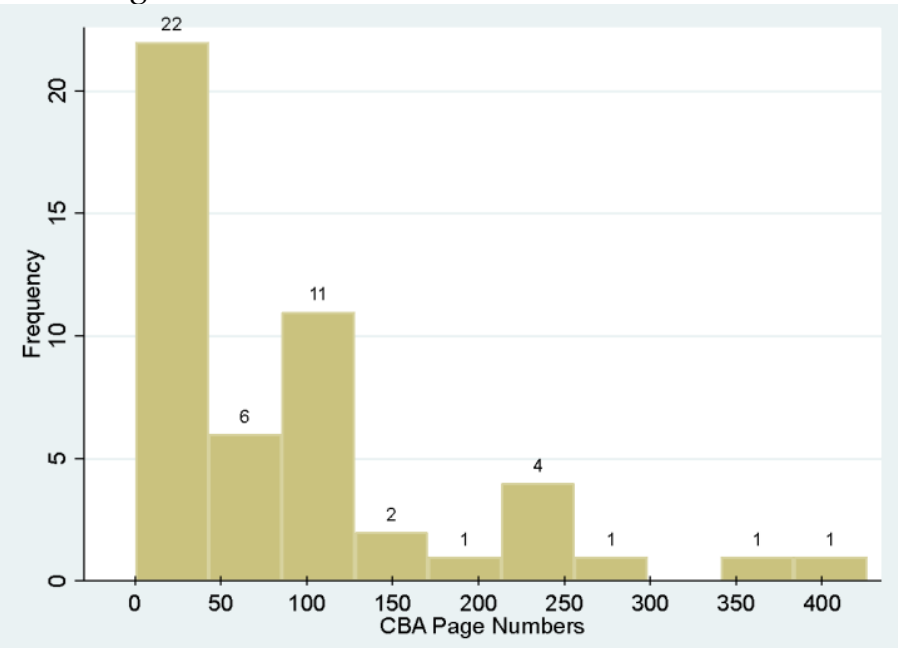

Dependent Variable 
To measure my dependent variable, I investigated whether the school district had adopted a vaccination and testing mandate. To elaborate, I searched the internet whether school districts had the option of requiring teachers to either receive a COVID19 vaccination or take periodic tests for COVID-19. I used this rather than a COVID-19 vaccination-only mandate because of the politically polarizing nature of the COVID-19 vaccines. While teachers' unions and school districts want to preserve the health and safety of staff and students, both groups want to retain teachers. Giving teachers the option of not taking the vaccine avoids some of the political backlash while still incentivizing high vaccination rates. Protests have been a common form of expression of disagreement with these policies (McAndrew, 2021; Downey, 2021). There were instances where school districts were not allowed to adopt vaccination mandates because of state law. Texas, for example, has many school districts that were coded as not having vaccination and testing mandates because of an executive order banning COVID-19 vaccine mandates. The few school districts that adopted a strict COVID-19 vaccination mandate were still coded as having a vaccination and testing mandate because it is essentially still the same effect in both cases - incentivizing higher vaccination rates. As an anecdote, this appears to be mostly exclusive to the largest of school districts. Four of the largest five school districts have a vaccination only mandate, with one other school district in this sample outside of the largest five school districts (Philadelphia City School District, the 19th largest district in the country) to have a vaccination only mandate. Figure 3 displays information on the vaccination and testing mandates variable. This binary variable is a 0 where there is no vaccination and test mandate and a 1 where there is a vaccination and testing mandate. With the average being 0.428, Figure 3 indicates that most school districts did not adopt a vaccination and testing mandate.

\section{Figure 3}

Number of Vaccination and Testing Mandates

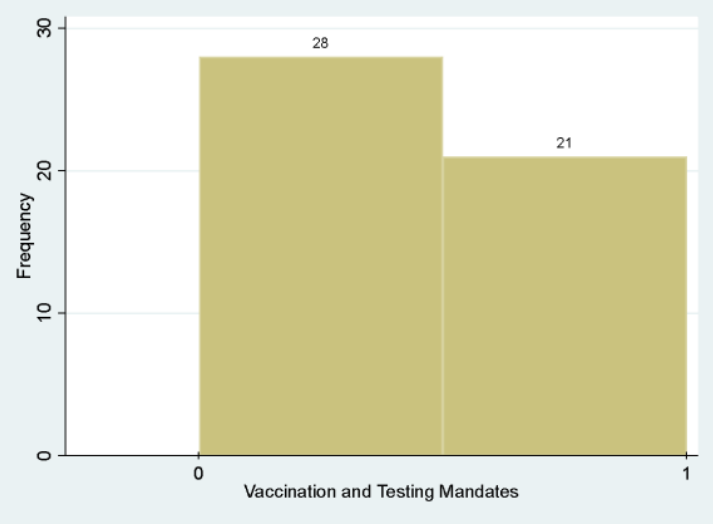

\section{Analysis}

Using two linear regression models, I find support for both of my hypotheses. Table 1 describes the relationship between the Vaccination and Tests dependent variable and the CBA. Table 2 examines the effect of CBA Page Numbers on school district policy. Starting with Model 1, there is a moderately strong, positive relationship when a teachers' union has a CBA with its school district and when a vaccination and test mandate is in place in the school district. Specifically, the presence of a CBA is statistically significant at the 0.05 level, with a coefficient of .333. Substantively, this shows that a district that negotiated a CBA with a union is $33 \%$ more likely to have a vaccination mandate than a district without a CBA. Therefore, hypothesis A has support, and I can reject the null hypothesis.

\section{Table 1}

Model 1, Presence of CBA

\begin{tabular}{|l|l|l|}
\hline Vaccination and tests & Coefficient & Standard Error \\
\hline Presence of CBA & $0.3333^{* *}$ & 0.1375 \\
\hline Constant & $0.2381^{* * *}$ & 0.104 \\
\hline Observations & 49 & \\
\hline
\end{tabular}

\section{Table 2}

Model 2, CBA Page Numbers

\begin{tabular}{|l|l|l|}
\hline Vaccination and tests & Coefficient & Standard Error \\
\hline CBA Page Number & $0.001^{*}$ & 0.001 \\
\hline Constant & $0.324^{* * *}$ & 0.09 \\
\hline Observations & 49 & \\
\hline
\end{tabular}

Note: all models estimated using a linear regression. $* * * p<.01 ; * * p<.05 ; * p<.10$ 
Model 2 tests the second hypothesis. This model, on the other hand, is only statistically significant at the 0.10 level, with a coefficient of .001. This means that for every 1 unit increase in the number of pages in a CBA, there is a $1 \%$ greater probability that a school district will adopt a vaccination mandate. Regardless, the statistical significance means that I can reject the null hypothesis at the 0.10 level. The results are more interesting when one considers that some of the school districts with CBAs that have a high page count also have a strict vaccination mandate rather than a vaccine and testing mandate. For example, New York City Public Schools, Los Angeles Unified, and the City of Chicago (SD 299) all have CBAs with 238 pages, 426 pages, and 381 pages, respectively, and strict vaccination mandates. However, there are counter points, like Clark County ${ }^{1}$ and Philadelphia City which both have a strict vaccination mandate. Both have CBAs under 100 pages but possess strict vaccine mandates. Conversely, Dade County, the fourth largest school district in the country, which also has a 274page CBA, does not have a strict vaccination mandate. Further testing could be done to isolate whether there is a threshold for page numbers that may predict the adoption of a vaccination mandate.

\section{Conclusion}

Does the strength of a teachers' union predict whether a school district will adopt a COVID-19 vaccination mandate? In this paper, I argued yes. Unions have a vested interest in keeping their members safe. Their previous actions to delay school reopoenings suggests that they would be in favor of vaccination mandates. However, due to political polarization surrounding vaccines and COVID-19, a strict vaccination mandate may be unfeasible. So, I posit that the combination of a vaccination and testing mandate would be a better option to encourage better vaccination rates against COVID-19.

To test my research question, I used the presence and page length of collective bargaining agreements (CBAs) for my independent variables to measure teachers' unions' strength. This is similar to how Marianno et al. (2021) conducted their study based off of Bachrach and Baratz (1962) theory of interest group power. CBAs are a useful application of Bachrach and Baratz long face of power. CBAs are a good representation of a union's ability to negotiate favorable policies relative to the school districts they operate in. Union's negotiating power allows them to directly influence policies at the source of the policy and does not require the public to be involved to support the union's endeavors. My first hypothesis was, a school district that has a CBA with a teachers' union is more likely to adopt a vaccine and testing mandate than a school district without a CBA. I also follow Marianno et al.'s (2021) methodology of using the page numbers of a CBA to represent the strength of the union. The more pages in the CBA indicates more rights, regulations, and other guarantees in favor of the union. My second hypothesis is the more pages in a CBA between a teacher's union and a school district the more likely the school district will adopt a vaccination mandate.

I find support for both of my hypotheses. A school district that has a CBA with a teachers' union is $33 \%$ more likely to adopt a vaccination and testing mandate compared to a school district without a CBA. The second hypothesis has weaker evidence, but the findings are still statistically significant. For every 1 unit increase in the number of pages in a CBA, there is a .001 higher chance that a school district will adopt a vaccination and testing mandate. Substantively, this has interesting applications for unions that have very large CBAs with school districts. School districts like New York City Public Schools, Los Angeles Unified, and the City of Chicago (SD 299) have CBAs with 238 pages, 426 pages, and 381 pages, respectively, and all have strict vaccination mandates compared to a vaccination and testing mandates. This is not a rule of thumb given that Philadelphia City School District and Clark County School district also have vaccination mandates and CBAs under 100 pages, or that Dade County with a 274-page CBA does not have a strict vaccination mandate. Regardless it is an interesting observation and worthy of future study.

This study does have some limitations. I was unable to account for some of the political polarization

\footnotetext{
1 Clark County's vaccination mandate was just passed under a vote by the school board and has yet to be implemented as of the time this paper was written
}

Spectra Undergraduate Research Journal - 2022 - Volume 2, Issue 1 
that may explain the adoption of vaccination and testing mandates across the country. A number of studies showed there were relationships between vote shares for President Trump and the likelihood of schools teaching in person in the fall of 2020. Trump vote shares in school districts may also predict whether or not school districts adopt vaccination and testing mandates. This would be a good area for future study. Another area for future study is employing Bachrach and Baratz's (1962) short face of power in addition to the long face, to see if there would be different findings from Marianno et al.

This paper adds to the literature of unions' abilities to achieve policy goals, particularly in rapidly changing and dynamic political environments. A great deal of effort and power is required to alter policies that had to be made with such short notice. Capturing how unions reacted in the midst of a global pandemic is important for future widespread emergencies and how unions or other similar groups would react then. This also adds to discussions about political polarization and how it impacts policy measures meant to protect people - in this case school populations. Especially in contemporary politics, polarization can alter the policy playing fields that actors work in. This paper gives clues as to the entrenched powers that have advantages in the face of rampant polarization.

\section{Acknowledgements}

I am incredibly proud and happy to have finished this paper to end my undergraduate career, and it could not have been done without the support of UNLV faculty and my friends that I have made over the past four years.

First, I would like to thank Dr. Elizabeth Maltby. Dr. Maltby is a major reason for my continued academic endeavors. Her encouragement for me to join the advanced Masters track at UNLV has eased me into graduate classes and made me sure it is the right decision for me. Additionally, her help this past semester is immense and I do not think words alone express the gratitude I have for her. I am sure she is sick of my emails and me plaguing her office hours. I do not know what she saw in me in her methods course (possibly that I was one of the few people consistently participating), but I am blessed that she gave me that push to move forward.
I also want to thank my Brookings family. I am very lucky to be surrounded by such passionate, intelligent people for a job and for school. They have helped me explore my own passions and been a constant support for the past several years. I specifically want to thank Caitlin Saladino, William Brown, Ashley LeClair, Andre Perry, John Hudak, and Makada Henry-Nickie for taking me in and mentoring me. It is a rarity to have a single great mentor, but it is extraordinary to have all of these people taking me under their wing.

Next, I want to thank Olivia Cheche. Besides being my source for comedic relief for the past year, she has been an amazing friend, peer, and colleague. Her diligence in academia and life is an inspiration to me - and I hold her in the highest of regards.

Lastly, I must thank my family. While we have our ups and downs, I am fortunate to have a great support system at home. They put me through college. They put up with me studying a weird subject area. And they have done so with love to last a thousand lifetimes.

\section{References}

Bachrach, P., \& Baratz, M. S. (1962). Two faces of power. American Political Science Review, 56(4), 947-952. https://doi.org/10.2307/1952796

Cowen, J. M., \& Fowles, J. (2013). Same contract, different day? An analysis of teacher bargaining agreements in Louisville since 1979. Teachers College Record, 115(5), 1-30.

Dean, A., McCallum, J., Kimmel, S., \& Venkataramani, A. (2021). Iowa school districts were more likely to adopt COVID-19 mask mandates where teachers were unionized. Health Affairs $\quad 40(8), \quad 1270-1276$. https://doi.org/10.1377/hlthaff.2020.02518.

DeAngelis, C. A., \& Makridis, C. (2021). Are school reopening decisions related to union influence? Social Science Quarterly. 102(5), http://dx.doi.org/10.2139/ssrn.3684867.

Downey, D. (2021, November 12). Protest against COVID vaccine mandate led by Inland Empire teachers and parents. Press Enterprise. https://www.pe.com/2021/10/18/californiasschool-coronavirus-vaccine-mandate-protestedby-inland-empire-parents-teachers/ 
Feuer, W. (2020). Trump pushes to reopen schools, says closures will probably cause 'More Death'. CNBC. https://www.cnbc.com/2020/07/30/trumppushes-to-reopen-schools-says-closures-willprobably-cause-more-death

Grossmann, M., Reckhow, S., Strunk, K. O., \& Turner, M. (2021). All states close but red districts reopen: The politics of in-person schooling during the COVID-19 pandemic. Educational Researcher. https://doi.org/10.3102/0013189x211048840.

Hartney, M. T. \& Finger, L. K. (2021). Politics, markets, and pandemics: public education's response to COVID-19. Perspectives on Politics, $1-17$.

https://doi.org/10.1017/s1537592721000955.

Hemphill, A. A., \& Marianno, B. D. (2021). Teachers' unions, collective bargaining, and the response to Covid-19. Education Finance and Policy, 16(1), 170-182. https://doi.org/10.1162/edfp_a_00326.

Hoxby, C. M. (1996). How teachers' unions affect education production. The Quarterly Journal of Economics, 111(3), 671-718. https://doi.org/10.2307/2946669.

Ingle, K. W., \& Wisman, A. R. (2017). Extending the work of Cowen and Fowles: A historical analysis of Kentucky teacher contracts. Educational Policy, $32(2)$, 313-33. https://doi.org/10.1177/0895904817741544.

Jordan, P. W. (2021). What congressional Covid funding means for $\mathrm{K}-12$ schools. FutureEd. https://www.future-ed.org/what-congressionalcovid-funding-means-for-k-12-schools/

Marianno, B. D., Hemphill, A., Loures-Elias, A. P. S., Garcia, L., \& Cooper, D. (2021). Power in a pandemic: Teachers' unions and their responses to school reopening [Working Paper]. University of Nevada, Las Vegas Working Papers. http://bradmarianno.faculty.unlv.edu/workingpapers/

McAndrew, S. (2021). WCSD says no attendance dip amid nationwide protest of potential COVID-19 vaccine mandates. Reno Gazette Journal. https://www.rgj.com/story/news/2021/10/18/wash oe-county-school-district-not-talking-coronavirusvaccine-mandates-protests/8516557002/

McDonnell, L. M., \& Pascal, A. (1988). Teacher unions and educational reform. Educational
Resources Information Center (ERIC), https://eric.ed.gov/?id=ED293837

National Center for Education Statistics (NCES). (2021, November 12). Digest of education statistics, $2017 . \quad$ NCES. https://nces.ed.gov/programs/digest/d17/tables/dt1 7_215.30.asp

Rose, H., \& Sonstelie, J. (2010). School board politics, school district size, and the bargaining power of teachers' unions. Journal of Urban Economics 67(3), 438-50. https://doi.org/10.1016/j.jue.2010.01.001

Strunk, K. O. (2011). Are teachers' unions really to blame? Collective bargaining agreements and their relationships with district resource allocation and student performance in California. Education Finance and Policy. https://direct.mit.edu/edfp/article/6/3/354/10141/A re-Teachers-Unions-Really-to-Blame-Collective

Tomasik, M. J., Helbling, L. A., \& Moser, U. (2020). Educational gains of in-person vs. distance learning in primary and secondary schools: A natural experiment during the COVID -19 pandemic school closures in Switzerland. International Journal of Psychology, 56(4), 566-76. https://doi.org/10.1002/ijop.12728 